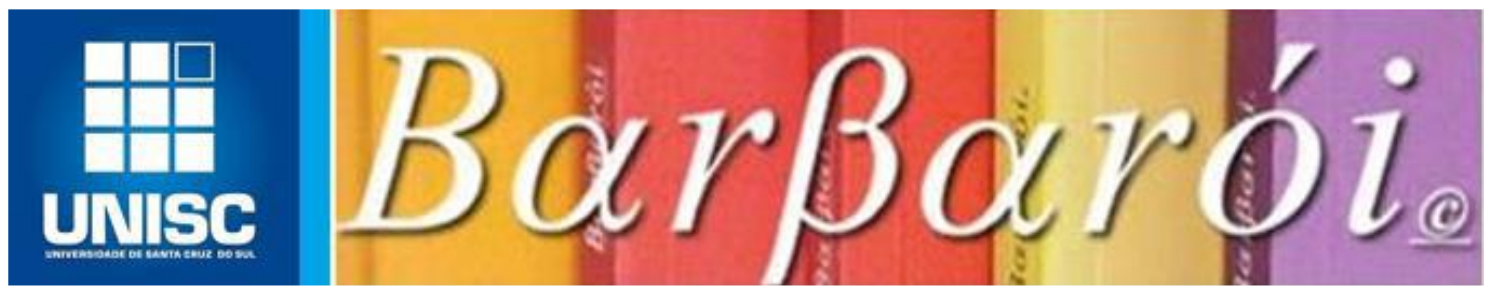

\title{
O RETORNO AO SERVIÇO DE POLICIAIS MILITARES GAÚCHOS APOSENTADOS: UM ESTUDO SOBRE OS FATORES MOTIVADORES
}

DOI: http://dx.doi.org/10.17058/barbaroi.v0i0.11577

\author{
$*$ \\ Régis Brum Nunes \\ Brigada Militar do Estado do Rio Grande do Sul-BMRS - Brasil \\ Jarbas Dametto \\ Universidadede Passo Fundo-UPF-Brasil \\ Cleide Fátima Moretto \\ Universidade de Passo Fundo - UPF-Brasil
}

\section{Resumo}

Após o processo de aposentadoria, muitos policiais militares do estado do Rio Grande do Sul, optaram por retornar ao trabalho na instituição Brigada Militar. O retorno voluntário desses policiais é amparado por lei estadual, desde 1994, observando-se, desde então, que um número significativo de profissionais aderiu a essa possibilidade. Este estudo objetivou identificar os motivos que levam parte dos policiais militares a retornarem ao trabalho policial após a obtenção da aposentadoria. Frente a tal intento, realizou-se um estudo do tipo transversal e descritivo, na forma censitária, contemplando 109 Policiais Militares do Comando Regional de Polícia Ostensiva do Planalto (CRPO/P), com sede em Passo Fundo (RS), pertencentes ao Corpo Voluntário de Militares Inativos da Brigada Militar, na faixa etária entre 45 e 64 anos. Focalizou-se quatro categorias prévias de análise: características sociodemográficas e pessoais,padrão de aposentadoria e renda, percepção do trabalho e motivos do retorno. Os dados foram tratados por meio de estatística descritiva simples e cotejados com as perspectivas teóricas da Psicologia Humanista de Maslow. Os resultados apontam as necessidades de estima e autorrealizaçãocomo principaiselementos motivadores do retorno à instituição, que incluem a necessidade de sentir-se útil e integrado a uma instituição, bem como à identificação com a profissão.

Palavras-chave: Polícia militar. Aposentadoria. Trabalho. Motivação.

\section{Introdução}

A aposentadoria é uma fase aguardada por muitos trabalhadores ao longo de suas trajetórias profissionais. É nesse período que a maioria das pessoas espera obter o retorno do 
investimento e dedicação de muitos anos trabalhados. Para França et al. (2013) é durante o envelhecimento, após anos destinados ao processo de trabalho, que muitas pessoas desejam se desvincular de atividades laborais, utilizando-se da aposentadoria para esse fim. Com isso, a aposentadoria seria um novo começo e uma oportunidade de concretizar projetos que não foram possíveis em razão do tempo dedicado ao trabalho formal. Para esses autores, uma vez que o processo de envelhecimento difere de pessoa para pessoa, é problemático tentar fixar até mesmo uma idade ideal para a aposentadoria.

A aposentadoria, como destacam França, Menezes e Siqueira (2012), é uma decisão incerta, acompanhada por muitas ambivalências, que vão desde a idade da concessão, formas de acesso, situação econômica, condições de saúde e outros fatores. A falta de preparação do trabalhador, tanto adulto maduro como o idoso, para a protelação ou a inclusão na aposentadoria, mostra-se com um dos principais fatores responsáveis pela indecisão durante o período de pré-aposentadoria. A esse respeito, a Política Nacional do Idoso (Lei $\mathrm{n}^{\circ} 8.842$, de 04/01/1994) menciona que tanto as empresas públicas quanto as privadas devem criar programas de preparação para a aposentadoria com antecedência mínima de dois anos antes do afastamento do idoso, mas sem menção aos trabalhadores de menos idade (BRASIL, 1994).

Um dos profissionais que costuma obter a aposentadoria em um período relativamente precoce é o policial militar, pois, conforme a Lei Complementar 10.990/97 (Estatuto dos Servidores Militares da Brigada Militar do Rio Grande do Sul) ao trabalhar 30 anos, ou atingir a idade entre 55 e 59 anos, o policial já está apto à obtenção da aposentadoria (RIO GRANDE DO SUL, 1997). Contudo, por não haver lei específica para não idosos em fase de préaposentadoria, a instituição Brigada Militar, até o presente momento, não disponibiliza de um programa de auxílio aos servidores em processo de pré-inatividade. A esse respeito,Antunes e Parizotto (2012) alertam que é necessário analisar o modo pelo qual a aposentadoria é efetivada, uma vez que, quando esta ocorre de maneira abrupta, sem que o profissional pense sobre ela, parece haver uma maior dificuldade de adaptação à nova realidade.

No caso dos policiais militares, a adaptação durante o período da reserva remunerada, que corresponde à aposentadoria dos demais trabalhadores, pode se apresentar de maneira mais dificultosa. Nessa perspectiva, França (2009) relata que, como ocorre em diversas instituições, muitos trabalhadores têm dificuldade de se desligar das organizações por conta de um sentimento de possível perda do companheirismo dos colegas, perda de statussocial, perda financeira, entre outros. Essa dificuldade de desprendimento também é observada por 
Queiroz (2007), quando argumenta que os empregados não veem mais as organizações como obrigação de sobrevivência e sim como uma extensão de sua família.

Em relação aos policiais militares, cabe considerar a intensa construção identitária em torno de elementos como a disciplina, a farda, o papel social do militar, a grupalidade, dentre outros,que são experimentadas em razão da dedicação exclusiva desses sujeitos para com a instituição, uma série de experiências e recursos simbólicos que são abruptamente deixados de lado após a aposentadoria. Fonseca (2001) argumenta que, ante o seu próprio envelhecimento e com a aposentadoria, estes profissionais convivem com a ruptura desses ideais, tanto em nível pessoal como frente ao imaginário coletivo, gerando consequências sobre a qualidade de sua vida.

No Brasil, mais especificamente no estado do Rio Grande do Sul, o retorno de policiais militares aposentados ao trabalho institucional vem ocorrendo de maneira considerável. Com o advento da Lei estadual $n^{\circ}$ 10.297, de 16 de novembro de 1994, que criou o Corpo Voluntário de Militares Estaduais Inativos $(\mathrm{CVMI})^{1}$, um número significativo de policiais militares aposentados decidiu retornar ao trabalho na instituição. Nos regulamentos e na cultura militar, o termo reserva remunerada equivale à aposentadoria, ou seja, o profissional na condição de aposentado é denominado na corporação como inativo ${ }^{2}$. O Policial Militar aposentado retorna às atividades para atuar especificamente em locais ${ }^{3}$ prédefinidos pela lei e por meio da Nota de Instrução Administrativa $\mathrm{n}^{\circ}$ 004.4-RH, documento interno da corporação. Ainda, conforme este documento, durante o processo de retorno ao trabalho na instituição, os Policiais Militares são submetidos a exames, testes de aptidão física, mental e avaliação do comportamento, para então, tornarem-se hábeis a retornar ao trabalho. Após, recebem um treinamento destinado à readaptação para o retorno à atividade $\mathrm{e}$ uma série de benefícios, dentre eles: gratificação especial de retorno à atividade; fidelidade da instituição em relação ao regime de trabalho de 40 horas semanais; vale-refeição mensal; licença para tratamento de saúde própria ou de pessoa da família, se necessário; licença paternidade ou maternidade; afastamento por luto ou núpcias; férias anuais com a percepção

\footnotetext{
${ }^{1}$ Os CVMI's caracterizam-se por um grupo de policiais militares aposentados, que retornaram as atividades institucionais de forma voluntária, após a obtenção da aposentadoria.

$2 \mathrm{O}$ uso do termo inativo justifica-se pela nomenclatura institucional. Há que se ressaltar, e a literatura recomenda, que a inatividade não é sinônimo de aposentadoria.

${ }^{3}$ Reforço ao policiamento de escolas públicas estaduais; escolas especiais mantidas e/ou administradas pelas entidades que prestam atendimento e assistência às pessoas portadoras de deficiência; no policiamento de guarda dos prédios do Ministério Público e do Tribunal de Contas do Estado. A norma prevê ainda, a atuação desses profissionais no policiamento de guarda dos prédios da corporação, condução e operação de viaturas de Bombeiros, além de atividades administrativas específicas.
}

Barbarói, Santa Cruz do Sul, n.55, p.<215-233>,jul./dez. 2019 
do respectivo terço remuneratório; percepção do $13^{\circ}$ salário anual e proporcional; diárias de viagem, no caso de serviços específicos; entre outros.

Como afirmam Canizares e Jacob Filho (2011), muitos desses profissionais, provavelmente, retornem à atividade com o intuito de obter mais renda para a família, pois atrelar a aposentadoria à diminuição da renda é uma prática usual em sujeitos na transição à aposentadoria. De outra parte, podem existir outras motivações para os aposentados permanecerem no mercado de trabalho. Zanelli e Silva (1996) e Zanelli (2012) destacam que o trabalho é fundamental para o desenvolvimento pessoal e reconhecimento social, o que resulta em dificuldades de desvinculação por parte do aposentado. A existência dessas motivações de retorno também é corroborada por Barbosa e Traesel (2013), uma vez que os autores reconhecem que muitos outros fatores podem extinguir-se com o fim da vida profissional, fatores como a vida social, a valorização perante a sociedade, a referência na profissão, os compromissos, os horários, o sentimento de "ser útil".

Neste contexto, abre-se espaço para a releitura da construção teórica de Maslow para as motivações. Sampaio (2009) destaca que Maslow apoia sua teoria na visão de homem racional imbuído de impulsos e desejos, dotado decorporalidade, ainda que não circunscrita a ela, detentor de uma vida interior, que também resulta de sua associação com a cultura e a sociedade, com interação interpessoal ao mesmo tempo em que revela elementos coletivos. Configura-se, assim, como complementa o autor, um "todo integrado e organizado" com capacidade de fazer escolhas e de criar significado para a realidade.Portanto, “[...] há que se pensar em um homem quelida com múltiplos anseios, capazes de o mobilizarem, nasdiferentes instâncias sociais da vida: a organização laboral, afamília e a vida em sociedade" (SAMPAIO, 2009, p. 10).

Diante dessa realidade, busca-se identificar os principais fatores motivadores do retorno dos policiais militares à instituição, para que, a partir de um olhar humanista a esta questão, possam ser pensadas outras experiências de trabalho e de aposentadoria junto a esta classe.

\section{Método}

Este artigo apresenta um recorte de um estudo transversal e descritivo em abordagem quantitativa, que utilizou levantamento de dados primários obtidos com os próprios profissionais, em 32 municípios de atuação dos CVMI's na área do CRPO Planalto. O estudo mais amplo contou com a aplicação de um formulário de pesquisa construído a partir de um 
instrumento utilizado por Armstrong-Stassen (2008) em um estudo com trabalhadores ativos e aposentados que retornaram ao trabalho após a aposentadoria. A população do estudo contempla 120 policiais militares do sexo masculino, pertencentes à instituição Brigada Militar que, após a obtenção da aposentadoria retornaram à instituição na graduação de sargentos e estão em pleno desempenho das atividades. Optou-se por trabalhar com a população total e não com uma amostra em razão do número reduzido de sujeitos envolvidos. Em função da condição dos profissionais no período de realização, participaram do estudo 109 sujeitos. A inclusão de participantes exclusivamente do gênero masculino, se deu em razão de não existirem policiais militares do sexo feminino aposentadas que retornaram à instituição na área do estudo. Foram excluídos os profissionais de outras graduações em razão da possível discrepância nos resultados em função da diferença salarial. A coleta de dados foi realizada entre os meses de setembro e novembro do ano de 2015. Durante todo o processo da pesquisa foram atendidos os critérios éticos de pesquisa com seres humanos ${ }^{4}$.

No presente estudo, as categorias características sociodemográficas e pessoais foram analisadas por meio das seguintes variáveis: idade, estado civil, número de filhos vivos, escolaridade, situação da moradia, condição de provisão na unidade familiar, número de dependentes, cidade de lotação. Além delas, o estudo concentra-se nas categorias perfil do trabalho, da aposentadoria e da renda e percepção do trabalho, da aposentadoria e do retorno. A primeira reúne as variáveis idade com que começou a trabalhar; ano de ingresso na corporação; tempo em que está aposentado; tempo de aposentadoria antes do retorno; tipo de aposentadoria; valor líquido mensal da aposentadoria; rendimento na corporação além do salário; outras rendas; origem das outras rendas. A segunda, por sua vez, contempla motivos para o retorno ao trabalho; centralidade do trabalho; identidade com a organização; relação esforço-recompensa.

Pesquisas vêm sendo realizadas no intuito de entender o que motiva o idoso a retornar ao trabalho, porém, estudos referentes ao retorno ao trabalho por parte dos policiais militares aposentados, tanto idosos como não idosos, ainda são inexistentes no que tange ao caráter científico. Além do mais, a literatura geralmente proporciona discussões sobre aposentados

\footnotetext{
${ }^{4} \mathrm{O}$ estudo foi aprovado pelo Comitê de Ética em Pesquisa da [...] (Parecer $\mathrm{n}^{\circ}$ 1.162.741). Depois de esclarecer os procedimentos do estudo, os 109 participantes assinaram o Termo de Consentimento Livre e Esclarecido (TCLE). Foram seguidas as diretrizes da Resolução CNS nº 466/12 do Conselho Nacional de Saúde sobre a participação de pessoas em pesquisas. Foram atendidos os aspectos éticos de consentimento da instituição Brigada Militar, de sigilo, anonimato e respeito aos valores do sujeito.
} 
idosos, todavia, no contexto do policial militar aposentado, a maior parte deles não se enquadra como idosos 5 .

A análise dos dados foi baseada na análise estatística descritiva simples, tais como frequência absoluta, frequência relativa, tabelamento cruzado e análise de correlação. Para o tratamento dos dados foi utilizado o programa estatístico SPSS, versão 22.0 para Windows (IBM, 2013). Os dados levantados foram interpretados sob a luz da Psicologia Humanista, tomando como recurso central a teoria de Abraham Maslow (1908-1970), conhecida como Hierarquia das Necessidades Humanas, usualmente referida como um aporte teórico clássico para a gestão de pessoas, mas que, como teoria da personalidade, lança parâmetros para a análise da vida humana em seus diversos aspectos, sendo o trabalho apenas um de seus componentes, que pode, ou não, assumir um papel de centralidade na experiência do sujeito.

\section{Análise e discussão dos resultados}

Foram analisadas, inicialmente, as características sociodemográficas e pessoais dos profissionais militares em estudo. As idades dos 109 policiais pesquisados variaram entre $45 \mathrm{e}$ 64 anos, com média de idade igual a 56,82 e moda 57 anos (Figura 1). Pode-se observar que $33,9 \%$ possuem idades entre 57 e 59 anos, aproximando-se dos 60 anos. Do total, apenas $27,5 \%$ podem ser classificados como idosos, apresentando idades entre 60 e 64 anos. A baixa média de idade pode ser explicada pela obtenção da aposentadoria por meio de legislação diferenciada para funções de risco.

Figura 1 - Histograma da idade, frequência relativa (\%) dos policiais militares pesquisados.

\footnotetext{
${ }^{5}$ Para países em desenvolvimento, como é o caso do Brasil e, conforme o Estatuto do Idoso (BRASIL, 2003), considera-se idosa a pessoa com 60 anos ou mais de idade.

Barbarói, Santa Cruz do Sul, n.55, p.<215-233>,jul./dez. 2019
} 


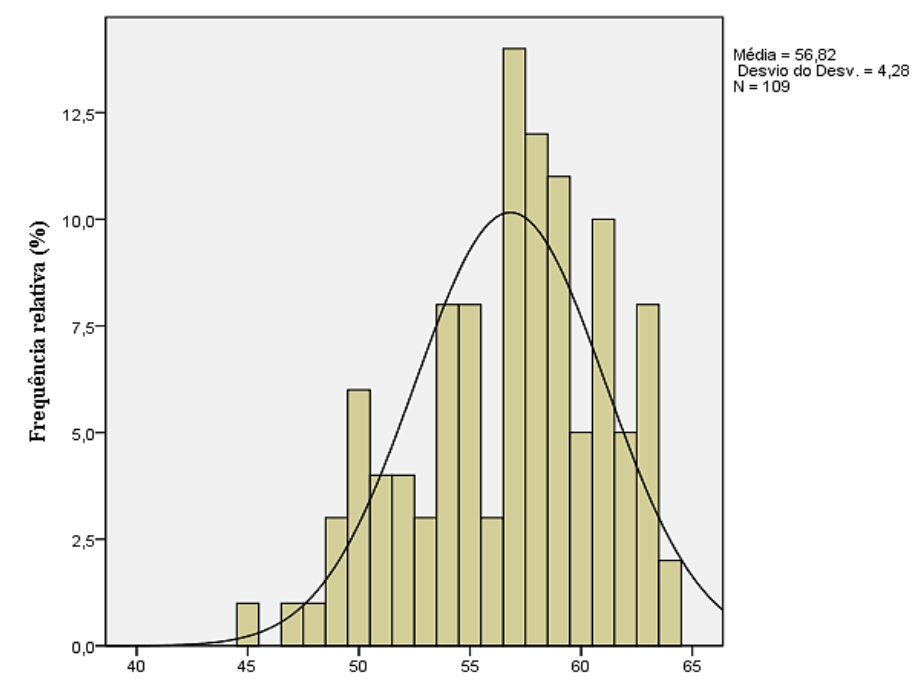

Fonte: primária, 2015.

Em relação ao estado civil, 89,9\% declararam ser casados ou estar na condição de união estável. A média de filhos dos participantes ficou em 2,58; mais de a metade dos participantes $(56,0 \%)$, declarou possuir até dois (2) filhos. Ao se observar o número de aposentados que possuem até três (3) filhos, a frequência acumulada fica em 85,3\%. A média do número de dependentes, incluído o participante, ficou em 2,64, indicando que a renda obtida é gasta com apenas uma pessoa, além do próprio entrevistado.

Em relação à escolarização, observa-se que, mesmo em número reduzido, 4,6\% não concluíram o ensino fundamental. Mais de a metade dos aposentados $(56,0 \%)$ declararam ter concluído o ensino médio e somente $2,8 \%$ o ensino superior completo.

A grande maioria $(92,7 \%)$ dos entrevistados possui casa própria; 6,4\% vivem em moradias alugadas e somente $0,9 \%$ reside na casa dos filhos e/ou parentes. Conforme Araújo et al. (2012), possuir casa própria proporciona ao aposentado maior capacidade de suporte familiar.Em relação à provisão na unidade familiar, $65,1 \%$ dos participantes relataram ser o chefe da família, suportando integralmente ou a maior parte das despesas do lar; 34,9\% relataram contribuir parcialmente com as despesas. O censo demográfico de 2010, nesses termos, evidenciou que $42,6 \%$ dos domicílios brasileiros, tem como chefe pessoas com 50 anos ou mais(IBGE, 2011). Essa evidência confirma a realidade de que, em diversos casos, o aposentado ainda continua sendo o provedor financeiro principal das unidades familiares (BULLA; KAEFER, 2003; CAMARANO, 2002; PEIXOTO, 2004).

No que diz respeito à aposentadoria, é interessante observar que quase a metade dos pesquisados $(45,9 \%)$ estão aposentados durante um período de 10 anos ou menos, já $54,1 \%$ 
estão aposentados há mais de 10 anos. Esta última evidência vem ao encontro dos resultados obtidos por Khoury et al. (2010), que identificaram que 14,0\% dos aposentados continuam trabalhando depois de 10 anos de efetivação da aposentadoria.

Após a aposentadoria, mais de a metade, ou seja, 56,0\% permaneceram pelo período máximo de um (1) ano aposentado antes de voltar à instituição. A frequência acumulada aumenta para $73,4 \%$ quando se inclui o período de até dois anos. A média de anos de aposentadoria antes do retorno à instituição ficou em 2,22 anos. A esse respeito, o estudo de Armstrong-Stassen,Schlosser e Zinni (2012) verificou que os trabalhadores que ficaram menos tempo na condição de aposentados foram os mais propensos a voltar ao trabalho remunerado do que os que tinham permanecido mais tempo na aposentadoria.

No que se refere ao tipo de aposentadoria, para 98,2\% dos participantes ela ocorreu pela opção de atingir o tempo mínimo para solicitação, já 1,8\% se aposentaram ao atingir a idade máxima para solicitação. Em relação ao valor do rendimento, o valor médio da aposentadoria ficou em $R \$ 4.657,34$, variando entre $R \$ 4.000,00$ e $R \$ 5.000,00$, tendo como valor de maior frequência $\mathrm{R} \$ 4.800,00$ (Figura 2).

Figura 2 - Histograma do valor da aposentadoria, em $\mathrm{R} \$$, dos policiais militares pesquisados.

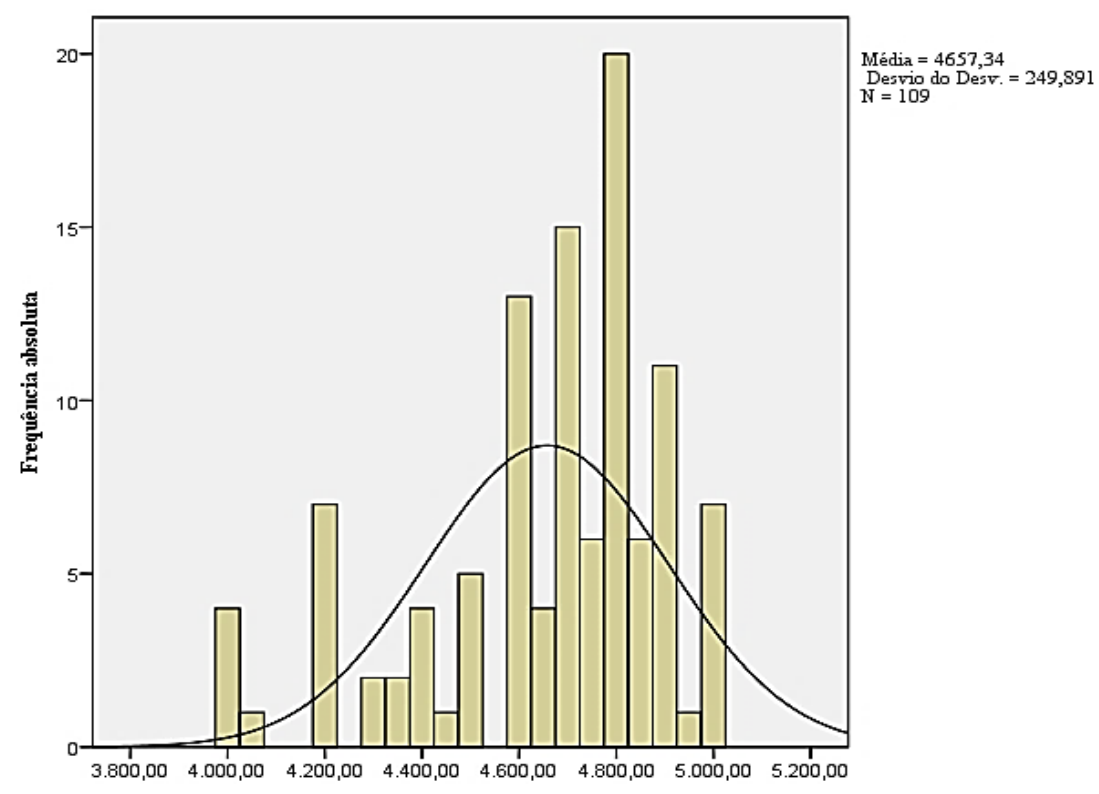

Fonte: primária, 2015.

A média da gratificação recebida pelo retorno à atividade na instituição após a aposentadoria ficou em $\mathrm{R} \$ 1.650,55$; ovalor mínimo, em $\mathrm{R} \$ 1.480,00$ e o máximo em $\mathrm{R} \$$ Barbarói, Santa Cruz do Sul, n.55, p.<215-233>, jul./dez. 2019 
1.800,00. Portanto, os policiais estariam retornando à ativa para receber um rendimento adicional de cerca de 33,0\% do que receberiam como aposentadoria. Este dado, aliado aos motivos indicados para o retorno, sugerem que a complementação da renda possivelmente não seja o elemento motivador mais importante. Sobre esse ponto, Camarano (2002) atribui o retorno dos aposentados a fatores de natureza socioeconômica, especialmente à necessidade de aumentar a renda. Já Bulla e Kaefer (2003) acrescentam que, há algumas décadas atrás, quem se aposentava não precisava continuar trabalhando, pois a renda da aposentadoria bastava para o sustento do aposentado, o que hoje não necessariamente acontece. No que se refere a outras rendas, $75,2 \%$, declararam não possuir rendas além das provenientes da instituição, já o restante $(24,8 \%)$ relatou possuir rendas referentes a aluguéis, pensões e outros.

No que tange aos principais motivos de retorno ao trabalho institucional (Tabela 1), mencionados pelos policiais, intuito principal do presente estudo, a condição de "Sentirem-se úteis e produtivos" sobressaiu-se sobre as demais (100,0\%), seguido da "Identificação com a profissão" (98,1\%) e "Necessidade de complementação da renda" (86,3\%). Em todas as alternativas apresentadas pela Tabela 1, foi utilizada a soma dos atributos "Concordo" e "Concordo totalmente" para chegar ao resultado final prevalente.

Tabela 1 - Motivos atribuídos para o retorno ao trabalho na instituição pelos policiais militarespesquisados.

\begin{tabular}{lcccccc}
\hline $\begin{array}{l}\text { Motivos de retorno ao trabalho } \\
\text { na instituição }\end{array}$ & $\begin{array}{c}\text { Discordo } \\
\text { totalmente } \\
(\%)\end{array}$ & $\begin{array}{c}\text { Discordo } \\
(\%)\end{array}$ & $\begin{array}{c}\text { Neutro } \\
(\%)\end{array}$ & $\begin{array}{c}\text { Concord } \\
\text { o } \\
(\%)\end{array}$ & $\begin{array}{c}\text { Concordo } \\
\text { totalmente } \\
(\%)\end{array}$ & $\begin{array}{c}\text { Total } \\
(\%)\end{array}$ \\
\hline Se sentir útil e produtivo & 0,0 & 0,0 & 0,0 & 30,3 & 69,7 & 100,0 \\
\hline $\begin{array}{l}\text { Identificação com a profissão } \\
\text { Necessidade }\end{array}$ & 0,0 & 0,0 & 1,8 & 79,9 & 18,3 & 100,0 \\
\hline $\begin{array}{l}\text { complementação da renda } \\
\text { Não ter recebido preparação } \\
\text { para a aposentadoria }\end{array}$ & 1,7 & 2,8 & 9,2 & 50,5 & 35,8 & 100,0 \\
\hline $\begin{array}{l}\text { Sentir necessidade de conviver } \\
\text { com os colegas }\end{array}$ & 0,0 & 5,5 & 15,6 & 48,6 & 29,4 & 100,0 \\
\hline $\begin{array}{l}\text { Ter se aposentado jovem } \\
\text { demais }\end{array}$ & 0,9 & 5,5 & 26,7 & 59,6 & 7,3 & 100,0 \\
\hline
\end{tabular}

Fonte: primária, 2015.

Grande parte dos estudos que analisam os motivos de retorno dos aposentados ao trabalho refere-se, principalmente, à motivação financeira, contudo, percebe-se que no universo policial militar estudado, a necessidade de se sentir útil e produtivo prevalece perante as outras. Esta, por sua vez, pode estar associada ao compromisso de servir à 
sociedade, concepção que perpassa as motivações dos policiais militares (TAKAHASHI; LEMOS; SOUZA, 2015).

De outra parte, a depender da idade dos aposentados pesquisados, controlando os sujeitos pesquisados em relação a ser idoso (+ de 60 anos) ou não, nota-se que para os idosos o atributo "Concordo totalmente" em relação ao motivo "Se sentir útil e produtivo" é mais frequente $(76,5 \%, \mathrm{n}=30)$.

A identificação com a profissão foi referida como a segunda maior motivação para o retorno ao trabalho na instituição Brigada Militar. Assim, observa-se que os resultados encontrados até aqui sugerem que os fatores psicossociais preponderaram sobre o fator financeiro. No estudo de Nummer (2005), realizado com policiais da Brigada Militar no município de Lajeado (RS), com idades entre vinte e quarenta e cinco anos, durante os anos de 2007 a 2009, observou-se que a construção da identidade social dos policiais militares vai se originando após o ingresso na corporação, durante o curso de formação. Segundo a autora, é nesse período que os alunos policiais já mostram um sentimento de pertencimento à corporação, unificando suas identidades à instituição.

No que diz respeito ao motivo de retorno como a identificação com a profissão, entre os idosos deste estudo, houve uma frequência menor dos atributos "Concordo" e "Concordo totalmente". Somente $27,5 \%$ dos policiais idosos fizeram referência a esse motivo, em oposição $72,5 \%$ dos não idosos para a amostra total.

A alternativa "Necessidade de complementação da renda familiar" foi observada como terceiro motivo de retorno ao trabalho por parte dos policiais aposentados pesquisados. Esse fato pode estar relacionado parcialmente à constatação de Peixoto (2004), uma vez que o autor entende que a casa das pessoas mais velhas vem se transformando em suporte socioeconômico e afetivo, tanto para filhos como netos. A pesquisa de Celich e Baldissera (2010), realizada com uma amostra de 60 idosos, demonstrou que os baixos valores dos benefícios previdenciários, somados ao prolongamento da vida, fazem com que muitos deles continuem trabalhando para garantir uma renda suficiente para suprir as suas necessidades individuais e de seus familiares; isso porque muitos continuam sendo chefes de família. Este motivo se mostrou mais frequente para os atributos "Concordo" e "Concordo totalmente" para os não idosos pesquisados $(72,5 \%, \mathrm{n}=79)$.

Outro item que merece destaque foi a questão da preparação para a aposentadoria, pois $78,0 \%$ dos participantes indicaram a importância de se criar um programa de preparação para a aposentadoria na instituição Brigada Militar, que os auxiliasse no momento da decisão da 
aposentadoria. França (2002) sustenta que para que a transição trabalho-aposentadoria seja efetivada de maneira mais tranquila, é fundamental que sejam propostos programas de preparação para a aposentadoria nas organizações. Em relação a este motivo, os atributos "Concordo" e "Concordo totalmente" foram prevalentes para os não idosos (72,5\%).

O motivo de retorno ao trabalho no intuito de conviver com os colegas pode ser entendido na argumentação de Queiroz (2007), que coloca que, para muitos profissionais, o trabalho é tido como uma extensão de sua família, já que é lá que eles dedicam boa parte do dia, vivendo praticamente para a empresa. Mesmo que em número reduzido, o retorno ao trabalho em razão do policial ter se aposentado jovem demais foi observado em 66,9\% dos participantes. França (2009) salienta que um dos motivos do retorno ao trabalho após a aposentadoria advém de a aposentadoria ter chegado para pessoas com boas condições gerais de trabalho.

Analisando os atributos "Concordo" e "Concordo Totalmente", sobre a relação dos participantes com o trabalho atual (Tabela 2), 96,4\% relataram acreditar que o trabalho realizado por eles é muito valioso para a organização, $89,0 \%$ acreditam que as coisas mais importantes que acontecem em suas vidas envolvem o trabalho. "A principal satisfação em minha vida vem do meu trabalho" foi indicada em $81,6 \%$ dos entrevistados. Caso fossem livres para escolher, 83,4\% optariam em continuar trabalhando na instituição Brigada Militar. Salvo circunstâncias imprevistas, 80,8\% permaneceriam na organização indefinidamente, já $79,8 \%$ esperam continuar trabalhando tanto quanto possível na organização.

Tabela 2 - Relação do profissional militar pesquisado com o trabalho atual

\begin{tabular}{|c|c|c|c|c|c|c|}
\hline $\begin{array}{c}\text { Relação do profissional com o trabalho } \\
\text { atual }\end{array}$ & $\begin{array}{c}\text { Discordo } \\
\text { totalmente } \\
(\%)\end{array}$ & $\begin{array}{c}\text { Discord } \\
\text { o } \\
(\%)\end{array}$ & $\begin{array}{l}\text { Neutr } \\
\text { o }(\%)\end{array}$ & $\begin{array}{c}\text { Concord } \\
\text { o }(\%)\end{array}$ & $\begin{array}{l}\text { Concordo } \\
\text { totalmente } \\
(\%)\end{array}$ & $\begin{array}{c}\text { Total } \\
(\%)\end{array}$ \\
\hline $\begin{array}{l}\text { As coisas mais importantes que } \\
\text { acontecem para mim envolvem o meu } \\
\text { trabalho }\end{array}$ & 0,0 & 2,8 & 8,3 & 57,0 & 32,1 & 100,0 \\
\hline $\begin{array}{l}\text { A principal satisfação em minha vida vem } \\
\text { do meu trabalho }\end{array}$ & 0,0 & 4,6 & 13,8 & 54,1 & 27,5 & 100,0 \\
\hline $\begin{array}{l}\text { Salvo circunstâncias imprevistas, eu } \\
\text { permaneceria nesta } \\
\text { indefinidamente }\end{array}$ & 0,0 & 4,6 & 14,6 & 40,4 & 40,4 & 100,0 \\
\hline $\begin{array}{lrr}\text { Se fosse completamente livre para } \\
\text { escolher, eu preferiria } \\
\text { trabalhando nesta organização }\end{array}$ & 0,0 & 5,5 & 11,0 & 28,5 & 55,0 & 100,0 \\
\hline $\begin{array}{l}\text { Espero continuar trabalhando tanto } \\
\text { quanto possível nesta organização }\end{array}$ & 0,0 & 2,8 & 17,4 & 49,5 & 30,3 & 100,0 \\
\hline $\begin{array}{l}\text { Eu sou recompensado de forma justa pelo } \\
\text { montante de esforço que eu coloco no } \\
\text { trabalho }\end{array}$ & 10,1 & 50,5 & 25,7 & 11,9 & 1,8 & 100.0 \\
\hline $\begin{array}{l}\text { Eu sou recompensado de forma justa, } \\
\text { considerando as responsabilidades que eu }\end{array}$ & 10,1 & 52,3 & 26,6 & 9,2 & 1,8 & 100,0 \\
\hline
\end{tabular}




\begin{tabular}{l}
\hline tenho \\
$\begin{array}{l}\text { Eu sou recompensado de forma justa, } \\
\text { tendo em vista minha experiência }\end{array}$ \\
$\begin{array}{l}\text { O trabalho que faço é muito valioso para } \\
\text { a minha organização }\end{array}$
\end{tabular}

Fonte: primária, 2015.

Nesse sentido, a análise de correlação para os motivos de retorno ao trabalho e a percepção do trabalho foram significativos, demonstrando, em nível de 1\%, uma correlação forte de 0,843 entre "As coisas mais importantes que acontecem para mim envolvem o meu trabalho" e a "A principal satisfação em minha vida vem do meu trabalho". Uma correlação igualmente forte $(0,808)$ foi evidenciada entre "Salvo circunstâncias imprevistas, eu permaneceria nesta organização" e "Se eu fosse completamente livre para escolher, eu preferiria continuar trabalhando nesta organização" e de 0,782 entre a primeira e "Espero continuar trabalhando tanto quanto possível nesta organização". Aqui se percebe a relação do comprometimento afetivo com a intenção de permanecer na instituição, fato já evidenciado por Armstrong-Stassen e Schlosser (2011).

Em se tratando dos atributos "Discordo Totalmente" e "Discordo", 77,0\% discordaram ao serem indagados se são recompensados de forma justa pela organização, tendo em vista sua experiência. Ainda, 62,4\%, acreditam não serem recompensados de forma justa tendo em vista as responsabilidades que possuem no trabalho e, 60,6\% acreditam não serem recompensados de forma justa pelo montante de esforço colocado no trabalho. Tal dado reforça as considerações anteriores, de que os maiores elementos motivadores se dão na esfera emocional, e não financeira.

A abordagem de Maslowtem como um recorte de sua obra, a "hierarquia das necessidades humanas", comumente apresentada como uma "pirâmide de necessidades", que apresenta os fatores motivadores da relação do sujeito com o mundo e consigo mesmo. Tal hierarquia é composta por cinco níveis, indo de elementos básicos, como as necessidades orgânicas, até experiências humanas complexas, como a sensação de realização pessoal. Os fatores que mobilizam o sujeito são permutados por outros, à medida que necessidades de níveis mais rudimentares são contempladas, emergindo, então, necessidades mais complexas (FEIST; FEIST; TOMI-ANN, 2015, MASLOW, 1970).

Retomando esta perspectiva teórica, considera-se que o primeiro nível de necessidades humanas remete a necessidades fisiológicas, de caráter nutricional, reprodutivo, de homeostase e de bem-estar físico, contemplando tudo o que é necessário para a adequada existência orgânica do sujeito. Este nível não difere o ser humano de qualquer outra espécie 
animal, já que é das necessidades de um organismo em relação ao meio, que se está falando. O segundo nível já traz especificidades humanas (tal qual todos os demais), ele remete a necessidades de segurança, que dizem respeito a busca por garantir o suprimento de necessidades básicas ao longo do tempo, como seguridade social, remuneração estável, aposentadoria, casa própria, dentre outros fatores que geram certas "garantias" em relação à experiência futura. O terceiro nível, denominado afetivo-social, ou necessidades de amor $e$ pertencimento, suscita o indivíduo a estabelecer relações interpessoais, de compartilhamento e intimidade, que podem ser desenvolvidas em espaços laborais, mas também familiares, religiosos, comunitários, de estudo e amizade. O quarto nível, necessidades de estima, remetem a busca por sentimentos de autoconfiança, perícia, respeitabilidade eboa reputação, trata-se de uma busca por sentir-se importante e apreciado junto ao seu meio social.

O quinto nível remete a experiências de autorrealização, necessidade que, segundo Maslow, se diferencia das demais por não ter como origem o sentimento de falta ou de deficiência de algo ou de alguma experiência, mas sim uma busca por experiências de efetivo crescimento. Este último nível seria difícil de atingir, pois demanda o adequado atendimento das necessidades dos demais níveis. Trata-se de uma busca íntima por realização, que pode ser observada em pessoas que "nunca param" de estudar, trabalhar, aprender, crescer pessoalmente, dedicar-se a suas obras pessoais ou coletivas, seguindo esta empreitada com sentimentos de prazer, e não de obrigação ou pesar. Diante dessa condição, é o desejo, e não mais a falta, que move o sujeito (HALL; LINDZEY; CAMPBELL, 2000, MASLOW, 1970).

Pode-se inferir que o público estudado possui necessidades de caráter fisiológico e de segurança supridas a contento. As condições financeiras após a aposentadoria remetem a uma remuneração relativamente suficiente, bem como a estabilidade dessa remuneração. Também, a maioria dos sujeitos reporta possuir casa própria, o que os desonera de despesas consideráveis. Outro elemento que sustenta essa proposição é que a remuneração obtida pelos reservistas no seu reingresso à corporação é significativamente inferior aos vencimentos da aposentadoria, representando cerca de um quarto de sua renda total, remuneração esta que poderia ser superada por outras atividades laborais fora da corporação. A sensação de recompensa financeira insuficiente frente à atividade e a experiência prévia, também foram referidas pela maioria dos policiais abordados. Infere-se que a remuneração possui sua importância, mas não seria um elemento motivador predominante, tanto pelas condições econômicas dos sujeitos, quanto pela remuneração limitada oferecida no reingresso. 
As necessidades de nível socioafetivo compõem os motivos de retorno, mas não de modo absolutamente predominante. A necessidade de "conviver com os colegas" é menos referida que aquelas que se relacionam a sentimentos de identidade e autoestima e até mesmo aquelas relativas à remuneração.

Como ponto praticamente consensual entre os sujeitos abordados tem-se a ocorrência de considerações afirmativas quanto a tópicos envolvendo o sentimento de utilidade e identificação com a profissão. Aspectos que remetem à livre opção pelo trabalho de policial, a sensação de relevância e pertinência e ao desejo de ser um membro da organização pelo maior tempo possível também ganham destaque. Tais achados remetem a fatores motivadores que contemplam o nível de estima e, possivelmente, também, de autorrealização.

Problematizando tais resultados, e acatando o pressuposto maslowiano de que não contemplar as necessidades humanas prementes remete à emergência de sofrimento ou adoecimento (HALL; LINDZEY; CAMPBELL, 2000, MASLOW, 1970), cabe considerar em que medida a carreira de policial militar cerceia o indivíduo de outras formas de interação social e de sua inscrição em outras experiências coletivas ou individuais capazes de gerar um efeito de consolidação de autoestima e experiências de autorrealização, condição esta que tornaria o trabalho na corporação uma experiência indispensável ao bem-estar emocional desses sujeitos.

Tal ponderação deixa em aberto a questão de se o retorno remete a um desejo de voltar ao trabalho, ou à dificuldade de desligamento de uma função repleta de atributos simbólicos,uma espécie de temor frente a umasensação de perda identitária.É possível que o denominado "espírito de corpo" ou o sentimento de pertencimento à "grande família brigadiana, como refere Urquia (2019), expliquem tal dificuldade em um contexto profissional marcados pela união e coesão frente a um cenário adverso.

\section{Considerações finais}

O presente estudo confirmou que os policiais militares se aposentam precocemente em relação à população em geral. Do total de entrevistados, apenas $27,5 \%$ possuíam mais de 60 anos e mais da metade deles está aposentada há mais de 10 anos. No que diz respeito aos motivo de retorno, foi possível evidenciar que os sargentos do Corpo Voluntário de Militares Inativos da Brigada Militar na região do CRPO Planalto retornam ao trabalho na Instituição principalmente por motivos de pertinência social e identificação com a profissão, elementos reforçados frente a frequente referênciaà fragilidade na recompensa financeira pelo trabalho 
executado diante de suas experiências e responsabilidades, de modo que a questão financeira parece menos relevante que a experiência laboral e seu valor afetivo e simbólico.

A relação afetiva que esses profissionais demonstraram ter pela profissão e pela instituição parece contribuir de maneira predominantepara a permanência ou retorno à corporação. Entretanto, tal evidência não necessariamente implica em um desejo de interação com os colegas, tópico menos relevante no levantamento realizado, antes, salienta-se a necessidade de manutenção de um papel sociale de um lugar em um contexto institucional, que proporcionam experiências que contemplam a preservação da autoestima, bem como a possibilidade de autorrealização.

Os resultados apontam para o peso da dimensão trabalho na construção identitária ao longo do ciclo de vida dos policiais militares, motivo pelo qual a aposentadoria poderá acarretar em adoecimento físico e psíquico. Dessa forma, reforça-se a importância do desenvolvimento e implementação de programas de preparação para a aposentadoria para este grupo de trabalhadores, na perspectiva de promoção da saúde e de qualidade de vida.

\title{
THE RETURN TO THE SERVICE OF RETIRED MILITARY POLICIES: A STUDY ON MOTIVATIONAL FACTORS
}

\begin{abstract}
After the process of retirement, many military police of Rio Grande do Sul state chose to return to work in the Military Brigade institution. The voluntary return of these officers is supported by state law since 1994. It is observed that a significant number of professionals adhered to this possibility. The study aimed to identify the motives why the military police officers to return to police work after reaching retirement. Face such attempt, was carried out a study cross-sectional and descriptive, the census form, includes 109 Military Police Regional Command Police Ostensive Plateau (CRPO / P), based in Passo Fundo (RS), belonging to the Volunteer Corps Military Inactive Military Police, aged between 45 and 64 years. It focuses on four previous categories of analysis, namely: socio-demographic and personal characteristics, standard retirement and income, perception of work and return reasons. The data were treated by means of simple descriptive statistics and collated with the theoretical perspectives of the Humanist Psychology of Maslow.The results point to the need for esteem and self-actualization as the main motivating factors for the return to the institution, which includes the need to feel useful and integrated with an institution, as well as to identify with the profession.
\end{abstract}

Keywords: Police Military. Retirement. Work. Motivaton. 


\section{EL RETORNO AL SERVICIO DE POLICIALES MILITARES GAÙCHOS JUBILADOS: UN ESTUDIO SOBRE LOS FACTORES MOTIVADORES}

\section{Resumen}

Después del proceso de jubilación, muchos policías militares del estado de Rio Grande do Sul, optaron por regresar al trabajo en la institución Brigada Militar. El retorno voluntario de esos policías es amparado por ley estatal desde 1994, observándose desde entonces que un número significativo de profesionales se ha adherido a esta posibilidad. Este estudio objetivó identificar los motivos que llevan a parte de los policías militares a retornar al trabajo policial despues de la obtención de la jubilación. En este sentido, se realizó un estudio del tipo transversal y descriptivo, en forma censitaria, contemplando 109 Policías Militares del Comando Regional de Policía Ostensiva del Planalto (CRPO / P), con sede en Passo Fundo (RS), pertenecientes al Cuerpo Voluntario de Militares Inactivos de la Brigada Militar, en el grupo de edad entre 45 y 64 años. Se enfocó cuatro categorías previas de análisis: características sociodemográficas y personales, patrón de jubilación y renta, percepción del trabajo y motivos del retorno. Los datos fueron tratados por medio de estadística descriptiva simple y cotejados con las perspectivas teóricas de la Psicología Humanista de Maslow. Los resultados apuntan a las necesidades de estima y autorrealización como principales elementos motivadores del retorno a la institución, que incluyen la necesidad de sentirse útil e integrado a una institución, así como a la identificación con la profesión.

Palabras clave: Policia militar. Jubilación. 3. Trabajo. Motivación.

\section{Referências}

ANTUNES, M. H.; PARIZOTTO, A. P. O Luto pela Aposentadoria. In: ESCUDEIRO, A. A morte e suas implicações para a vida. Fortaleza: LC Gráfica e Editora, 2012. p. 29-42.

ARAÚJO, C, K; et al. Vínculos familiares e sociais nas relações dos idosos. Revista Jovens Pesquisadores, Santa Cruz do Sul (RS), n. 1, p. 97-107, 2012.

ARMSTRONG-STASSEN, M., SCHLOSSER, F. Perceived organizational membership and the retention of older workers. Journal of Organizational Behavior, v. 32, n. 2, p. 319-344, 2011.

ARMSTRONG-STASSEN, M., SCHLOSSER, F., ZINNI, D. Seeking resources: Predicting retirees. Journal of Managerial Psychology, v. 27, n. 6, p. 615-635, 2012.

BARBOSA, T. M.; TRAESEL, E. S. Pré-aposentadoria: um desafio a ser enfrentado. Barbaroi, Santa Cruz do Sul (RS), n. 38, p. 215-234, jun. 2013.

BRASIL. Lei 8.842 de 04 de janeiro de 1994. Dispõe sobre a política nacional do idoso, cria o Conselho Nacional do Idoso e dá outras providências. Disponível em:https://www.planalto.gov.br/ccivil_03/leis/18842.htm. Acesso em: 16 nov. 2014.

BRASIL. Lei n. 10.741, de $1^{\circ}$ de outubro de 2003. Dispõe sobre o Estatuto do Idoso e dá outras providências. Diário Oficial da União, Brasília, 3 out. 2003. Seção 1, p. 1.

BULLA, L. C, KAEFER, C. O. Trabalho e aposentadoria: as repercussões sociais na vida do idoso aposentado. Revista Virtual Textos \& Contextos,Porto Alegre (RS), v. 2, n. 2, p. 1-8, dez. 2003. 
CAMARANO, A. A. Envelhecimento da População Brasileira: uma contribuição demográfica. Texto para discussão n. 858. Rio de Janeiro: IPEA, jan. 2002.

CANIZARES, J. C. L; JACOB FILHO, W. Fatores de risco à senilidade na transição à aposentadoria. Revista Brasileira de Geriatria e Gerontologia, Rio de Janeiro (RJ), v. 14, n. 3, p. 425-432, 2011.

CELICH, K. L. S; BALDISSERA, M. Trabalho após a aposentadoria: influência na qualidade de vida do idoso. A Terceira Idade, São Paulo (SP), v. 21, n. 49, p.53-66, nov. 2010.

FEIST, J.; FEIST, G. J.; TOMI-ANN, R. Teorias da personalidade. 8. ed. Porto Alegre: AMGH, 2015.

FONSECA, T. M. G. Prefácio - Envelhecer: Evolução ou Involução. In: CASTRO, O. P. (Org). Envelhecer: um encontro inesperado? Curitiba: Notadez, p. 15-17, 2001.

FRANÇA, L. H. de F. P. Repensando a aposentadoria com qualidade: um manual para facilitadores de programas de educação para aposentadoria em comunidades. Rio de Janeiro, CRDE/UnATI/UERJ, 2002. 55p.

FRANÇA, L. H. F. P. et al. Aposentar-se ou continuar trabalhando?: o que influencia essa decisão? Psicologia: Ciência e Profissão, Brasília (DF), v. 33, n. 3, p. 548-563, 2013.

FRANÇA, L. H. F. P. Influências sociais nas atitudes dos 'Top' executivos em face da aposentadoria: um estudo transcultural.Revista de Administração Contemporânea, Curitiba (PR), v. 13, n. 1, p. 17-35, mar. 2009.

FRANÇA, L. H. F. P.; MENEZES, G. S; SIQUEIRA, A. R. Planejamento para aposentadoria: a visão dos garis. Revisa Brasileira de Geriatria e Gerontologia, Rio de Janeiro (RJ), v. 15, n. 4, p. 733-745, out./dez. 2012.

HALL, C. S.; LINDZEY, G.; CAMPBELL, J. Teorias da personalidade. 4. ed. Porto Alegre: Artmed, 2000.

INSTITUTO BRASILEIRO DE GEOGRAFIA E ESTATÍSTICA - IBGE. Censo Demográfico 2010. Características da População e dos Domicílios. Rio de Janeiro: 2011.

KHOURY, H. T. T.et al. Por que aposentados retornam ao trabalho? O papel dos fatores psicossociais. Revista Kairós Gerontologia, São Paulo (SP), v.13, n.1, p.147-165, jun. 2010.

MASLOW, A. Introdução à psicologia do ser. Rio de Janeiro: Eldorado, 1970.

NUMMER, F. V. Ser polícia, ser militar: o curso de formação na socialização do policial militar. Niterói: EDUFF, 200.

PEIXOTO, C. E. Aposentadoria: retorno ao trabalho e solidariedade familiar. In: PEIXOTO, C. E. (Org.). Família e envelhecimento. Rio de Janeiro: FGV Editora, 2004. p. 57-84. QUEIROZ, B. L. The determinants of male retirement in urban Brazil. Nova economia, Belo Horizonte, v. 17, n. 1, p. 11-36, jan./abr. 2007. 
RIO GRANDE DO SUL (Estado). Brigada Militar. História da Brigada Militar.Porto Alegre, [s. d.].Disponível em:

https://www.brigadamilitar.rs.gov.br/Site/Institucional/Historia.aspx. Acesso em: 10 abr. 2016.

RIO GRANDE DO SUL (Estado). Brigada Militar. Nota de Instrução Normativa 004.4RH,de 10 de outubro de 2014. Porto Alegre, 2014a. Acesso restrito.Disponível em: https://intranet.bm.rs.gov.br/Estrutura/Pm3/Legislacao.aspx. Acesso em: 11 abr. 2016.

RIO GRANDE DO SUL (Estado). Decreto no 43.245, de 19 de julho de 2004. Aprova o Regulamento Disciplinar da Brigada Militar do Estado do Rio Grande do Sul. Diário Oficial do Estado: Porto Alegre, n. 137, p. 2, 20 jul. 2004.

RIO GRANDE DO SUL (Estado). Lei n 10.990, de 18 de agosto de 1997. Dispõe sobre o Estatuto dos Servidores Militares da Brigada Militar do Estado do Rio Grande do Sul e dá outras providências. Diário Oficial do Estado: Porto Alegre, n. 157, p. 1, 19 ago. 1997.

RIO GRANDE DO SUL (Estado). Lei n ${ }^{\circ} 14.449$, de 15 de janeiro de 2014. Altera o art. 1. ${ }^{\circ}$ da Lei n. ${ }^{\circ} 10.916$, de 03 de janeiro de 1997, e alteração posterior, que dispõe sobre a Gratificação Especial de Retorno à Atividade, prevista na Lei n. ${ }^{\circ}$ 10.297, de 16 de novembro de 1994, e altera o valor da Gratificação. Diário Oficial do Estado: Porto Alegre, n. 11, p. 1, 16 jan. 2014.

SAMPAIO, J. R. O Maslow desconhecido: uma revisão de seus principais trabalhos sobre motivação. Revista de Administração - RAUSP, São Paulo (SP), v. 44, n. 1, p. 5-16, jan./mar. 2009.

TAKAHASHI, A. R. W.;LEMOS, M. R.; SOUZA, C. P. S. Motivação no Serviço Públicoe Permanência na Carreira Militarda Polícia Militar doParaná/Brasil. Desenvolvimento em Questão, Ijuí (RS), v. 13, n. 29, p. 311-354, jan./mar. 2015.

URQUIA, I. S. A percepção do policial militar gaúcho sobre sua carreira: análise da ficha de desligamento preenchida ao ir para reserva remunerada. Revista Brasileira de Estudos de Segurança Pública, Goiânia (GO), v. 12, n.1, p. 12-18, jun. 2019.

ZANELLI, J. C. Processos Psicossociais, Bem-Estar e Estresse na Aposentadoria. Revista Psicologia: Organizações e Trabalho, Brasília (DF), v. 12, n. 3, p. 329-340, set./dez. 2012.

ZANELli, J. C.; SILVA, N. Programa de Preparação para a Aposentadoria.

Florianópolis: Insular, 1996.111 p.

Data de recebimento: 17/01/2018

Data de aceite: $13 / 11 / 2019$

\section{Sobre os autores:}

Régis Brum Nunesé Fisioterapeuta (Iesa). Especialista em Terapia Manual pelo Instituto Cenecista de Ensino Superior de Santo Ângelo (Iesa). Mestre em Envelhecimento Humano (UPF). Endereço Eletrônico: regis-nunes@ bm.rs.gov.br 
Jarbas Damettoé Psicólogo (UPF). Mestre e Doutor em Educação (UPF). Docente permanente do Programa de Pós-Graducação em Envelhecimento Humano (PPGEH), Universidade de Passo Fundo até fevereiro de 2019. Endereço Eletrônico: jarbas@upf.br

Cleide Fátima Moretto é Economista. Doutora em Teoria Econômica (USP). Pós-Doutorado em Psicologia Social (Universidade de Lisboa). Docente Permanente do Programa de PósGraduação em Envelhecimento Humano e do Programa de Pós-Graduação em Ciências Ambientais, Universidade de Passo Fundo. Endereço Eletrônico: moretto@upf.br 